\title{
Pérdida de flúor en piezas dentarias permanentes expuestas a refrescos: estudio comparativo in vitro
}

\author{
Núñez $P^{*}$, Olate $S^{*}$, Sanhueza $A^{* *}$, Núñez $G^{* * *}$
}

\section{RESUMEN}

Introducción: La exposición a refrescos y zumos de frutas se encuentra en constante aumento, siendo su principal característica la elevada acidez que presentan. Con estas alteraciones del equilibrio oral, la perdida mineral de la estructura dentaria es muy frecuente. Nuestro objetivo fue identificar la cantidad de flúor perdido de una pieza dentaria y comparar el efecto de dos bebidas presentes en el mercado.

Metodología: Se formaron dos grupos con 15 premolares cada uno, extraídos por indicación de ortodoncia; las piezas no presentaban patologías clínicas. El experimento consistió en la aplicación de un amortiguador de fuerza iónica para posteriormente llevarlo a una curva de calibración. Luego con un pH metro (ORION, modelo 920 A) se obtuvo los datos de pH de las bebidas; luego, durante 30 minutos se sumergió en la respectiva bebida para que con el electrodo se obtuviera los resultados de flúor presente. Se realizo la prueba estadística $T$ test para muestras independientes.

Resultados: cada vez más estudios confirman el impacto de los ácidos en la cavidad oral y su papel en la erosión dentaria. En nuestro estudio se aprecio un pH de 3,1 para la bebida de naranja y 2,5 para la bebida cola. Además arrojo diferencia significativa de la pérdida de flúor según la bebida aplicada $(\mathrm{p}<0,0001)$.

Conclusión: existe una importante pérdida de flúor de las piezas dentarias cuando se aplica una bebida ácida así como también existe diferencia significativa en el efecto de bebidas ácidas con solo 0,6 pH de diferencia.

Palabras clave: Erosión del esmalte, perdida de flúor, bebidas ácidas.

\section{SUMMARY}

Introduction: The exposure of soft drinks and fruit juices is constantly increasing and the main caracteristic of these beverages is the high acidity. This alteration of oral balance causes a more frequent loss of dental minerals. Our main objective was to identify the quantity loss of fluor of a tooth and compare this effect caused by two different kinds of soft drinks.

Methodology: 30 bicuspids were put in two different groups, 15 in each, extracted by ortodontics indication The tooth did not have evidence of clinical pathology. The experiment consisted in applying an ionic buffer, and later put the results in a calibration curve. So with a pH-Meter (Orion, model 920 a) the pH value was obtained. Then the tooth was submerged for 30 minutes in the soft drink and with the electrode the result of the presente quantity of fluor was obtained. The statistic T-test for independent proof where done.

Results: more and more research confirm the impact of the acid in the mouth and its role in dental erosion. In our research the $\mathrm{pH}$ value of the orange drink was 3.1 and the value for the coke drink was 2.5. Otherwise it shows a statistic difference of the loss of fluor by the different drinks $(p<0.0001)$.

Conclusion: An important loss of fluor occurs in the tooth when it gets in contact with an acid drink, as it also occurs a significant difference in the effect of acid drinks with a variation of $0.6 \mathrm{pH}$.

Key words: Enamel erosion, fluor loss, soft drinks.

Aceptado para publicación: Octubre 2005. 
$*$

$* *$
Departamento de Odontología Integral, Facultad de Medicina, Universidad de La Frontera, Temuco, Chile. Departamento de Matemáticas, Facultad de Ingeniería, Ciencias y Administración, Universidad de la Frontera, Temuco, Chile.

Departamento de Ciencias Básicas, Facultad de Medicina, Universidad de la Frontera, Temuco, Chile.

Núñez P, Olate S, Sanhueza A, Núñez G. Pérdida de flúor en piezas dentarias permanentes expuestas a bebidas de fantasía: estudio comparativo in vitro. Av. Odontoestomatol 2006; 22-2: 141-146.

\section{INTRODUCCIÓN}

En la dieta del hombre interactúan diferentes tipos de alimentos y diferentes formas de consumo; sin embargo, los ácidos líquidos o sólidos son comunes en todas partes del mundo. Aun más, las bebidas ácidas en occidente crecen en consumo cada vez más (1).

Las erosiones dentales, definidas como la destrucción mineral dentaria por sustancias químicas (2), son altamente influenciadas por tales ácidos; de esta forma, las erosiones se pueden presentar de forma subclínica o llegar hasta grandes destrucciones e importantes perdidas de estructura dentaria (2). En este sentido se han dirigido variadas investigaciones, coincidiendo ellas en la importancia del tipo de ácido consumido, tiempo de exposición al ácido, concentración del ácido e incluso la temperatura de la bebida $(3,4)$.

En la cavidad oral existen grandes protectores del medio, dentro de los cuales destaca la saliva. Sin embargo, la saliva presenta amplias variabilidades en su comportamiento. Así, el pH salival puede ser afectado por diversos factores como el tipo de dieta (5), demostrando con ello una alta variabilidad en las condiciones salivales entre distintos sujetos y en un mismo sujeto durante un día (6).

El flúor junto a sus diferentes aplicaciones son los métodos más utilizados en la prevención de caries (7). Este producto es incorporado a la estructura dentaria por complejos fenómenos bioquímicos que se traducen en una mayor resistencia a las agresiones ácidas ambientales (7).

En base a estas situaciones, se hace muy necesario cuantificar la perdida de flúor a causa del consumo de bebidas ácidas, presentes actualmente en el mercado.

\section{MATERIAL Y MÉTODOS}

El presente estudio in vitro fue de tipo comparativo entre dos bebidas distintas presentes en el mercado internacional, correspondientes a una misma compañía.

\section{Muestra}

Se utilizaron dientes premolares sanos extraídos por indicación de ortodoncia de sujetos entre 12 y 16 años de la misma ciudad; los sujetos relataron tener medidas de fluoruración solamente a través de los dentífricos fluorurados. Las piezas fueron inmediatamente sumergidas en suero fisiológico y congeladas en frío.

\section{Procedimiento en laboratorio}

Se determino la presencia de ión flúor en la bebida utilizando un amortiguador de fuerza iónica total (vendido comercialmente como TISAB) el que ajusta las muestras y los estándares a casi la misma fuerza iónica, es decir, ajusta las muestra a un mismo $\mathrm{pH}$. Se uso TISAB II dado que es utilizado para soluciones con baja fuerza iónica y con concentración de flúor menor a $2 \times 10^{-5}$ o 0,4 ppm y sin agentes complejos de flúor; este amortiguador tiene $\mathrm{pH}$ de 5,0 a 5,5 y debe usarse en combinación igual de volúmenes de TISAB II y muestras o estándares.

Para las mediciones de flúor liberado en diente se calibra el electrodo y se confecciona una curva de calibración. 


\section{Curva de calibración}

Se realiza una solución diluida de FNa a 10 ppm, tomando $0,1 \mathrm{ml}$ de solución de FNa a 100 ppm y diluyéndola en 1,0 ml. Luego, en un vaso precipitado de $150 \mathrm{ml}$, se depositan $50 \mathrm{ml}$ de agua destilada con $50 \mathrm{ml}$ de TISAB II agregándole 10 ppm según la Tabla 1. Posterior a ello se introduce el electrodo y se registran los potenciales $(\mathrm{mV})$ una vez estabilizada la lectura (3 minutos).

El resultado de la concentración corresponde a un potencial de electrodos en milivoltios; este corresponde a la actividad del ión flúor en la solución y es descrito por la ecuación de Nerst la que esta en directa relación con la concentración del ión.

Los datos obtenidos se grafican en un papel milimetrado donde el eje de las " $x$ " se ubico la concentración en menos logaritmo de la concentración y en el eje de las " $y$ " el potencial de electrodos en milivoltios. De esto se obtiene una curva graficada, la que debe ser lo mas próxima a la pendiente teórica del electrodo dada por la ecuación de Nerst.

\section{Medición de $\mathrm{pH}$ de las bebidas}

Se calibro el pH metro (ORION, modelo $920 \mathrm{~A}$ ) con 2 soluciones buffer. En un vaso precipitado de $50 \mathrm{ml}$ se introdujeron $30 \mathrm{ml}$ de la bebida y se midió con $\mathrm{pH}$ metro con lectura a los 10, 30, 40 y 60 minutos hasta determinar $\mathrm{pH}$ estable.

\begin{tabular}{|c|c|c|c|}
\hline \multicolumn{4}{|c|}{$\begin{array}{l}\text { TABLA 1.- CALIBRACIÓN } \\
\text { DE FLUORÍMETRO }\end{array}$} \\
\hline Paso & $\begin{array}{c}\text { Volumen } \\
\text { agregado (ml) }\end{array}$ & $\begin{array}{c}\text { Con } \\
\text { ppm }\end{array}$ & $\begin{array}{l}\text { entración } \\
\text { molaridad }\end{array}$ \\
\hline 1 & 0,1 & 0,01 & $1 \times 10^{-6}$ \\
\hline 2 & 0,1 & 0,02 & $2 \times 10^{-6}$ \\
\hline 3 & 0,2 & 0,04 & $4 \times 10^{-6}$ \\
\hline 4 & 0,2 & 0,06 & $6 \times 10^{-6}$ \\
\hline 5 & 0,4 & 0,10 & $1 \times 10^{-5}$ \\
\hline 6 & 2,0 & 0,29 & $2,9 \times 10^{-5}$ \\
\hline 7 & 2,0 & 0,48 & $4,8 \times 10^{-5}$ \\
\hline
\end{tabular}

\section{Medición de flúor en la muestra}

Los dientes descongelados a temperatura ambiente y lavados con agua destilada se depositaron e un vaso precipitado de $50 \mathrm{ml}$ a los que se le agrego 10 $\mathrm{ml}$ de la bebida. Una vez terminado el tiempo predeterminado se le agrego $10 \mathrm{ml}$ de TISAB II y se introdujo el electrodo para realizar la medición cuando se estabilizó la medida (3 minutos).

\section{Análisis estadístico}

Se realizo el test estadístico $\mathrm{T}$ test para muestras independientes.

\section{RESULTADOS}

Se obtuvo una muestra de 30 dientes extraídos por indicación de ortodoncia. Quince dientes se agregaron al grupo A con gaseosa frutal de naranja y 15 dientes correspondieron al grupo B con gaseosa cola.

En la tabla 2 se aprecia el $\mathrm{pH}$ de las bebidas. La bebida frutal naranja presento un $\mathrm{pH}$ de 3,1 en la medición realizada mientras que la bebida cola existió un $\mathrm{pH}$ de 2,5.

La tabla 3 muestra la cantidad de flúor perdido de la pieza dentaria al exponerse a la bebida frutal de naranja. El promedio de pérdida fue $0,088 \mathrm{ppm}$ con una desviación estándar de 0,0038 ppm. La tabla 4 exhibe la situación cuando se expuso los dientes a la bebida cola; en ella, el promedio de pérdida fue 0,114 ppm con una desviación estándar de 0,0187 ppm. Con la prueba estadística $T$ test para muestras independientes y con un grado de confianza de $95 \%$, se

\begin{tabular}{|lc|}
\hline \multicolumn{2}{|c|}{ TABLA 2.- pH DE LAS BEBIDAS } \\
EN ESTUDIO \\
\hline Gaseosa & $\mathrm{pH}$ \\
\hline Frutal Naranja & 3,1 \\
Cola & 2,5 \\
\hline
\end{tabular}




\begin{tabular}{|ccc|}
\hline \multicolumn{3}{|c|}{ TABLA 3.- FLÚOR PERDIDO DE CADA } \\
PIEZA DENTARIA DESPUÉS DE 30 \\
MINUTOS DE EXPOSICIÓN \\
\multicolumn{3}{|c|}{ A BEBIDA FRUTAL DE NARANJA } \\
\hline Diente & E (mV) & ppm \\
\hline 1 & 164,9 & 0,082 \\
2 & 163,1 & 0,088 \\
3 & 161,1 & 0,095 \\
4 & 162,0 & 0,092 \\
5 & 162,0 & 0,092 \\
6 & 163,3 & 0,088 \\
7 & 163,8 & 0,086 \\
8 & 163,9 & 0,086 \\
9 & 162,4 & 0,09 \\
10 & 164,1 & 0,085 \\
11 & 163,3 & 0,088 \\
12 & 162,1 & 0,092 \\
13 & 163,6 & 0,085 \\
14 & 164,5 & 0,083 \\
15 & 162,5 & 0,09 \\
\hline
\end{tabular}

\begin{tabular}{|ccc|}
\hline \multicolumn{3}{|c|}{$\begin{array}{c}\text { TABLA 4.- FLÚOR PERDIDO DE CADA } \\
\text { PIEZA DENTARIA DESPUÉS DE 30 } \\
\text { MINUTOS DE EXPOSICIÓN A BEBIDA } \\
\text { DE COLA }\end{array}$} \\
\hline Diente & E (mV) & ppm \\
\hline 1 & 158,8 & 0,104 \\
2 & 147,0 & 0,166 \\
3 & 155,9 & 0,117 \\
4 & 157,2 & 0,111 \\
5 & 161,3 & 0,095 \\
6 & 159,1 & 0,103 \\
7 & 159,9 & 0,100 \\
8 & 157,2 & 0,111 \\
9 & 154,5 & 0,124 \\
10 & 156,3 & 0,145 \\
11 & 158,2 & 0,106 \\
12 & 157,8 & 0,109 \\
13 & 158,8 & 0,104 \\
14 & 159,5 & 0,102 \\
15 & 156,1 & 0,116 \\
& &
\end{tabular}

estableció $p<0,0001$ demostrando diferencia estadística entre los grupos evaluados.

\section{DISCUSIÓN}

Nuestro estudio forma parte de un extenso trabajo que se desarrolla en la Unidad de Bioquímica del Departamento de Ciencias Básicas de la Universidad de La Frontera que incluye la caracterización y variaciones del componente salival en la cavidad oral. Los datos aportados por esta investigación son claros y concluyentes.

La dieta actual del hombre integra habitualmente bebidas gasificadas y jugos frutales de fuerte componente ácido. Por tal razón, las investigaciones en el área se han intensificado en los últimos años; además, las técnicas de laboratorio han mejorado la capacidad de conocer el papel de las diferentes interacciones en la cavidad oral.

Nuestros resultados señalan la gran acidez que presentan ambas bebidas, así como también la existencia de diferencia estadística en la pérdida de flúor por exposición a tales bebidas.

Diferentes situaciones son asociadas a la erosión dentaria $(3,4)$. Seow (8) demostró que la adición de agua o saliva al medio ácido disminuye significativamente los indicadores de desmineralización aunque fueron elevados volúmenes los utilizados; también la saliva artificial podría ser un ayudante importante (9).

En nuestro estudio se analizo solo dentición permanente; sin embargo, Lussi et al. (10) no demostraron que la perdida mineral fuera mayor en dentición temporal o permanente en similares condiciones de estudio, aunque la dureza inicial de la dentición permanente si era mayor.

Esta perdida mineral también afectaría a los materiales restauradores, como lo demostró AlipingMcKenzie (11), especialmente en los cementos de vidrio ionómero; si bien los tiempos de exposición en este estudio fueron largos (1 año), son relevantes toda vez que demuestran la alteración química de los materiales restauradores. 
En nuestro estudio al sumergir durante 30 minutos las piezas dentarias se obtuvo resultados que corroboraron nuestra hipótesis; es decir, cuando la bebida presento un menor $\mathrm{pH}$ (bebida cola $\mathrm{pH} 2,5$ ), los dientes tuvieron una mayor perdida de flúor, promediando $0.114 \mathrm{ppm}$. Con la bebida de mayor $\mathrm{pH}$ (bebida frutal $\mathrm{pH}$ 3.1) los dientes presentaron menor perdida de flúor y que promedio $0.088 \mathrm{ppm}$, demostrando diferencia estadísticamente significativa entre ambos.

Esto implica que "pequeñas" variaciones en el pH del liquido ( $\mathrm{pH}$ 0,6 de diferencia entre ambas bebidas) en una exposición de 30 minutos de las piezas dentarias desencadena importantes diferencias en la respuesta dentaria.

Estos hallazgos también se relacionan con los obtenidos por Larsen (12), quien estableció que mientras mas ácida era la bebida utilizada, mas fluoruro de calcio se disolvía. West (4) también concluye que las bebidas más ácidas causan mayor desmineralización dentaria. Hughes (13) señalo el rol del pH de los fluidos extraorales en la erosión del esmalte (por perdida mineral), mientras que Barbour (14) valoro también este aspecto, sugiriendo la incorporación de minerales a las bebidas ácidas.

Nuestras unidades muestrales pertenecían a diferentes sujetos y aunque la cantidad inicial de flúor de los dientes no pudo ser evaluada, la perdida de flúor sería inherente al sujeto del cual fue extraída la pieza. A pesar de esta limitación, concluimos que este estudio In Vitro se presenta como un método eficiente y eficaz en demostrar la agresión de las bebidas ácidas sobre los dientes, aseverando además que mientras mas ácida es la bebida existe mayor perdida de flúor de las piezas dentarias.

\section{BIBLIOGRAFÍA}

1. Dugmore CR, Rock WP. A multifactorial análisis of factors associated with dental erosion. Br Dent J 2004; 196: 283-6.

2. Zero DT. Etiology of dental erosion-extrinsic factors. Eur J Oral Sci 1996; 104: 162.
3. Shellis RP, Finke M, Eisenburger $M$, Parker DM, Addy $M$. Relationship between enamel erosion and liquid flow rate. Eur J Oral Sci 2005; 113 : 232-8.

4. West NX, Hughes JA, Addy M. Erosion of dentine and enamel in vitro by dietary acids: the effect of temperature, acid character, concentration and exposure time. J oral Rehabilitation 2000; 27 : 875-80.

5. Nuñez G. Estudo do metebolismo de carboidratos em núcleos de células de glandulas salivares durante o desenvolvimento da sialose. Universidad de Sao Paulo, 1990, Brasil.

6. Leone C, Oppenheim F. Physical and chemical aspects of saliva as indicators of risk for dental caries in humans. J Dent Educ 2001; 65: 1054-62.

7. Gómez S. Fluorterapia en odontologia para el niño y el adulto. $3^{\circ}$ ed.. Santiago de Chile, 2001. pp 31 - 39 , 217-27.

8. Seow WK, Thong KM. Erosive effets of common beverages on extracted premolar teeth. Australian Dental Journal 2005; 50 (3): 173-8.

9. Devlin H, Bassiouny MA, Boston D. Hardeness of enamel exposed to Coca-Cola and artificial saliva. J Oral Rehabilitation 2006; 33: 26-30.

10. Lussi A, Kohler N, Zero D, Schaffner M, Megert B. A comparison of the erosive potential of different beverages in primary and permanent teeth using an in vitro model. Eur J Oral Sci 2000; 108: 110-4.

11. Aliping-McKenzie M, Linden RWA, Nicholson JW. The effect of Coca-Cola and fruit juices on the surface hardeness of glass ionomers and 'compomers'. J Oral Rahabilitation 2004; 31: 1046-52.

12. Larsen MJ. Prevention by means of fluoride of enamel erosion as caused by soft drinks and orange juice. Caries Res 2001; 35(3): 229-34.

13. Hughes JA, West NX, Parker DM, van den Braak $\mathrm{MH}$, Addy $\mathrm{M}$. Effects of $\mathrm{pH}$ and concentration of 
citric, malic and lactic acids on enamel, in vitro. J Dent 2000; 28 (2): 147-52.

14. Barbour ME, Parker DM, Allen GC. Human enamel dissolution in citric acid as a function of $\mathrm{pH}$ in the range $2.30<$ or $=\mathrm{pH}<$ or $=6.30-\mathrm{a}$ nanoindentation study. Eur J Oral Sci 2003; 111 (3): 258-62.
CORRESPONDENCIA

Prof. Dr. Gabriel Núñez Burgos

Departamento de Ciencias Básicas, Facultad de Medicina.

Universidad de la Frontera, Temuco, Chile

email:gnunez@ufro.cl 